IZA DP No. 4189

Relational Contracts, Taxation and the Household

Patricia Apps

Ray Rees

May 2009 


\title{
Relational Contracts, Taxation and the Household
}

\author{
Patricia Apps \\ University of Sydney \\ and IZA \\ Ray Rees \\ University of Munich
}
Discussion Paper No. 4189
May 2009

IZA

P.O. Box 7240

53072 Bonn

Germany

Phone: +49-228-3894-0

Fax: +49-228-3894-180

E-mail: iza@iza.org

\begin{abstract}
Any opinions expressed here are those of the author(s) and not those of IZA. Research published in this series may include views on policy, but the institute itself takes no institutional policy positions.

The Institute for the Study of Labor (IZA) in Bonn is a local and virtual international research center and a place of communication between science, politics and business. IZA is an independent nonprofit organization supported by Deutsche Post Foundation. The center is associated with the University of Bonn and offers a stimulating research environment through its international network, workshops and conferences, data service, project support, research visits and doctoral program. IZA engages in (i) original and internationally competitive research in all fields of labor economics, (ii) development of policy concepts, and (iii) dissemination of research results and concepts to the interested public.
\end{abstract}

IZA Discussion Papers often represent preliminary work and are circulated to encourage discussion. Citation of such a paper should account for its provisional character. A revised version may be available directly from the author. 


\section{ABSTRACT}

\section{Relational Contracts, Taxation and the Household}

This paper applies the theory of relational contracts to make precise the idea that because households are engaged in a repeated non-cooperative game, Pareto efficient outcomes can be supported by self interest, given the specific pattern of specialisation and exchange which exists in the household. The household's choice of a particular solution from the resulting feasible set is found by the maximisation of a household welfare function, a generalisation of a suggestion originally made by Samuelson. This nests as special cases the objective functions used in currently popular models of households engaged in one-shot cooperative games. We take a specific example of such a household welfare function, characterise the determinants of the household utility distribution, and then apply the model to examine the effects of a move from joint to individual taxation. We show that on standard stylised facts, secondary earners are always better off absolutely, and define the conditions under which they will also be so relatively. This confirms the conclusions from models which concern themselves only with the across-household welfare distribution.

JEL Classification: D11, D13, H21, H24, H31, J12, J16, K36, N30

Keywords: relational contracts, households, allocations, taxation, welfare distribution

Corresponding author:

Patricia Apps

Faculty of Law

University of Sydney

Eastern Avenue, Camperdown Campus

Sydney NSW 2006

Australia

E-mail: p.apps@usyd.edu.au 


\section{Introduction}

There is now a large literature that takes seriously the idea that the model of the household as a single individual is inadequate for many purposes and that it is necessary to develop multi-person household models. ${ }^{1}$ This literature is dominated by models that see the household as playing a one-shot cooperative game. For example, the Nash bargaining models introduced by Manser and Brown (1980) and McElroy and Horney (1981), and further developed by Ott (1992), Lundberg and Pollak (1993) and Chen and Woolley (2001), rest on the assumption that the household members can make binding commitments. Likewise, the "collective model" of Browning and Chiappori (1998) assumes that the household maximises a form of utility function that is a weighted sum of the individual utility functions of its members. This, as Samuelson pointed out in his 1956 paper, assumes that the household reaches some sort of consensus that enables the application of the concept of a social welfare function to the modelling of household decision taking. The maximands in both these types of models possess the Pareto property, that the household always judges an increase in utility of any one of its members to be a good thing, other things being equal. It is then not surprising, even if not inevitable, that the household resource allocations produced by these models are Pareto efficient.

The Pareto efficiency of household allocations seems to be a reasonable requirement, since it is hard to see why a household would not want to exhaust all possibilities of costless improvement in the welfare of its members. Although of course Pareto efficiency would not necessarily follow if the household were modelled as behaving non-cooperatively, often a vague appeal is made to the idea that the household is in fact engaged in a repeated game, with an implicit appeal to the Folk Theorem providing the basis for the assumption of cooperative behaviour.

Beginning with Ott (1992), this casual assumption has however been challenged. She showed that if a household chooses its resource allocation in any given period by Nash bargaining, but the members could not commit themselves at one point in time to implement some particular allocation at any future period of time, then it is easy to construct a model in which the current allocation is not Pareto efficient. Lundberg and Pollak (2003) and Apps and Rees (2009b) present models with similar conclusions.

Descriptively speaking, it seems reasonable to assume that a household is engaged in a repeated game and cannot write exogenously enforceable agreements to implement cooperative behaviour. On the other hand, there are laws and social norms that at least to some extent regulate or influence behaviour within households, though ultimately, an important role must be played by the self interest of the members in supporting efficient allocations. In our view therefore, the theory of relational contracts, ${ }^{2}$ developed initially for labour markets and agency situations, provides an appropriate set of concepts with which to model

\footnotetext{
${ }^{1}$ For a survey see for example Apps and Rees (2009b).

${ }^{2}$ See for example MacLeod and Malcomson (1989), (1998) and Levin (2003).
} 
household decision making. In this paper we follow up this idea and apply the resulting model to a discussion of taxation policy.

\section{The Model}

\subsection{The Stage Game}

The household consists of a primary and a secondary earner, labelled respectively $i=1,2$. The primary earner divides his time between market work and leisure, the secondary earner spends in addition time in household production. ${ }^{3}$ The time constraints are therefore

$$
l_{1}+z_{1} \leq 1, \quad h_{2}+l_{2}+z_{2} \leq 1
$$

where $l$ denotes market labour supply, $h$ time spent in household production and $z$ leisure, the direct consumption of one's own time. Total time available is normalised to 1 . Market wage rates are $w_{i}$ and the household production function is

$$
y=k h_{2} \quad k>0
$$

with $y$ the total output of the household good. This implies that the opportunity cost or implicit price of the household good is

$$
p=\frac{w_{2}}{k}
$$

The household budget constraint is

$$
\sum_{i=1}^{2} x_{i} \leq \sum_{i=1}^{2} w_{i} l_{i}
$$

and we can collapse the constraints in (1), (2) and (4) into the single full income budget constraint

$$
\sum_{i=1}^{2}\left(x_{i}+p y_{i}+w_{i} z_{i}\right) \leq \sum_{i=1}^{2} w_{i}
$$

This determines the utility possibility set of the household. Define a household resource allocation as a vector $a=\left(x_{1}, y_{1}, z_{1}, x_{2}, y_{2}, z_{2}\right)$. Note that, given (1) (which will be satisfied as equalities) and (2), a value of $a$ implies also time allocations $l_{i}$ and $h_{2}$. Then, given the individual utility functions $u_{i}\left(x_{i}, y_{i}, z_{i}\right)$, which are strictly concave and increasing, and the feasible set of consumption vectors

$$
\Phi=\left\{a \in \mathbf{R}_{+}^{6} ; \quad \sum_{i=1}^{2}\left(x_{i}+p y_{i}+w_{i} z_{i}\right) \leq \sum_{i=1}^{2} w_{i}\right\}
$$

\footnotetext{
${ }^{3}$ We do not explicitly model the reasons for this specialisation. Apps (1981) however shows how it can result from a rational household decision in the face of labour market discrimination and loss of work-related human capital. For further discussion see Apps and Rees (2009b).
} 
the household's utility possibility set is

$$
\Omega=\left\{u=\left(u_{1}, u_{2}\right) \in \mathbf{R}_{+}^{2} ; \quad u_{i}=u_{i}\left(x_{i}, y_{i}, z_{i}\right), \quad a \in \Phi\right\}
$$

Given the assumptions on the utility functions this is a compact convex set and its upper boundary is of course the Pareto efficient set

$$
\Pi=\left\{u^{*} \in \boldsymbol{\Omega} ; \quad u_{1}^{*}=\arg \max u_{1} \text { s.t. } u_{2}^{*} \in \boldsymbol{\Omega}\right\}
$$

Note that the mapping $\omega: \Phi \longmapsto \Omega$ has an inverse $\phi: \Omega \mapsto \Phi$, giving the resource allocation required to generate a specific utility pair.

From Abreu (1986) we know that it suffices to consider the utility levels that would be generated in the worst punishment that can be inflicted on a player who deviates from some agreed allocation. In the present context this would correspond to the utility that would be achieved if the relationship were ended. Thus denote by $u_{i}^{0}$ the utility that would be achieved by $i$ in the next best feasible household to the one in question, and $u^{0}=\left(u_{1}^{0}, u_{2}^{0}\right)$. Then we make the assumption

A1: $u^{0} \in \operatorname{Int} \Omega$

so that there exist $\left(u_{1}, u_{2}\right) \in \Omega$ such that $u_{i}>u_{i}^{0}, i=1,2$. This simply ensures that household allocations exist that make it individually rational to remain within the household. Then define $\Omega^{0}=\left\{u \in \Omega ; u_{i} \geq u_{i}^{0}\right\} \subset \Omega$ and $\Pi^{0}$ as the corresponding subset of $\Pi$. We are interested in a household relational contract (HRC) that supports a household equilibrium resource allocation $a^{*}$ yielding a point $u^{*}=\omega\left(a^{*}\right) \in \Pi^{0}$. We now have to consider what such a contract could look like.

\subsection{Household Relational Contracts}

We assume, as in MacLeod and Malcomson (1989), (1998), that all outcomes are observable but not necessarily contractible. The relationship begins at date $\tau$, and we consider any time period $t \in[\tau, \infty)$.We assume that the primary earner, 1 , has a binding commitment to pay some amount of consumption $c$ to the secondary earner. This can be regarded as a level set by law, custom or social norm. He also, at the end of the period, makes a discretionary payment ${ }^{4} b$, which is contingent on 2 having adhered to the agreement. Thus the consumptions of the individuals are

$$
\begin{aligned}
& x_{1}=w_{1} l_{1}-c-b \\
& x_{2}=w_{2} l_{2}+c+b
\end{aligned}
$$

As well as specifying $b$, a household relational contract (HRC) specifies a feasible household resource allocation $a$. Then $b$ and $c$ have also to be feasible in the sense that given $a$, and therefore $l_{i}$ and $h_{2}$, they are such that $x_{i} \geq 0, i=1,2$.

\footnotetext{
${ }^{4}$ We use the term "payment" rather than "transfer" to emphasise that there is an underlying process of exchange, of market for household consumptiom, associated with the pattern of specialisation within the household.
} 
Denote the resulting set of $(b, c)$ pairs by $\Theta(a)$. Then, a HRC is a triplet $(a, b, c)$, with $a \in \Phi,(b, c) \in \Theta(a)$.

However, the set of feasible HRC's will be further restricted by incentive compatibility conditions. Let $U_{i t}$ denote the present value of the utility stream, and $u_{i t}$ the flow of utility in period $t$, that $i$ obtains under the given HRC, while $U_{i t}^{0}$ and $u_{i t}^{0}$ are the corresponding values for the outside options introduced in the previous section. Then if $\delta \in(0,1]$ is the one-period discount factor for both individuals, we have

$$
\begin{aligned}
& U_{i t}=u_{i t}+\delta U_{i t+1} \\
& U_{i t}^{0}=u_{i t}^{0}+\delta U_{i t+1}^{0}
\end{aligned}
$$

and individual rationality constraints are

$$
U_{i t} \geq U_{i t}^{0} \quad i=1,2
$$

Satisfaction of these constraint implies that the partners find it individually worthwhile to continue in the relationship.

Now, reneging on the HRC would take the following forms:

1 could refuse to make the payment $b$, having consumed his share of the household good $y_{1}$, in which case he would have the utility

$$
\hat{u}_{1 t}=\arg \max _{x_{1 t} z_{1 t}} u_{1}\left(x_{1 t}, y_{1}, z_{1 t}\right) \text { s.t. } x_{1 t}+w_{1} z_{1 t} \leq w_{1}-c
$$

Thus his gain from reneging would take the form of consuming the household good without fully paying for it what was agreed, and thereby enjoying more consumption of the market good and leisure for himself.

2 could refuse to supply the household good to 1 , thus losing the payment $b$, and so achieving the utility

$$
\hat{u}_{2 t}=\arg \max _{x_{2 t} y_{2 t} z_{2 t}} u_{2}\left(x_{2 t}, y_{2 t}, z_{2 t}\right) \text { s.t. } x_{2 t}+p y_{2 t}+w_{2} z_{2 t} \leq w_{2}+c
$$

Thus she could gain, for example, by using time not spent on household production for the primary earner to work more in the market, replacing at least to some extent the loss of consumption $b$.

Since reneging in period $t$ ends the relationship, ${ }^{5}$ each will obtain only their outside options from period $t+1$ on. Thus, we have the incentive compatibility or self enforcement constraints at each $t$

$$
U_{i t} \geq \hat{u}_{i t}+\delta U_{i t+1}^{0} \quad i=1,2
$$

We can rewrite this as

$$
U_{i t+1}-U_{i t+1}^{0} \geq\left(\hat{u}_{i t}-u_{i t}\right) / \delta>0 \quad i=1,2
$$

\footnotetext{
${ }^{5}$ Following MacLeod and Malcomson, we assume that reneging leads to a loss of trust that makes it impossible to restart the relationship. This finesses issues to do with renegotiation proofness.
} 
implying, given $\hat{u}_{i t}>u_{i t}$ that the individual rationality conditions in (13) for any $t>\tau$ cannot be satisfied as equalities for any feasible HRC. The requirement that both partners must find it in their interest to continue the relationship, i.e. that the HRC is self enforcing, shrinks the set of feasible HRC's relative to that implied by the outside options alone. Summing the two inequalities gives a necessary condition on the total utility surplus generated by the relationship

$$
\sum_{i=1}^{2}\left(U_{i t+1}-U_{i t+1}^{0}\right) \geq \sum_{i=1}^{2}\left(\hat{u}_{i t}-u_{i t}\right) / \delta>0
$$

Assuming that the set of self enforceable HRC's is not empty, it will also in general not be a singleton. How then does the household choose its equilibrium allocation? If we want to carry out a comparative statics analysis of the household's equilibrium choices it is essential to have an answer to this question, since, as Samuelson (1956) showed, the hypothesis that the household equilibrium allocation is Pareto efficient is not in general sufficient to place restrictions on changes in its equilibrium behaviour following changes in the exogenous variables determining that equilibrium.

We therefore propose that, given the set of feasible household allocations $\Phi^{0} \subset \Phi$ that can be supported by a feasible HRC, the household chooses its equilibrium allocation by solving the problem

$$
\max _{a} H\left(u_{1}, u_{2}, w_{1}, w_{2}\right) \quad \text { s.t. } a \in \Phi^{0}
$$

where the household welfare function $H$ is concave in $u_{1}, u_{2}$ for any given $w_{1}, w_{2}$ and has strictly positive and continuously differentiable derivatives $H_{1}, H_{2}$. Moreover, we assume

A2:

$$
\frac{\partial}{\partial w_{1}}\left[\frac{H_{1}}{H_{2}}\right]>0 \frac{\partial}{\partial w_{2}}\left[\frac{H_{1}}{H_{2}}\right]<0
$$

where $H_{1} / H_{2}$ is the household's marginal rate of substitution between 1 and 2's utility in the $\left(u^{1}, u^{2}\right)$-plane. The household's indifference curves in this plane at any point steepen with increases in $w_{1}$ and flatten with increases in $w_{2}$. These restrictions imply that an increase in individual $i$ 's wage rate always increases $i$ 's relative weight in the household welfare function. ${ }^{6}$

To explore the implications of this approach in a concrete context, we first present an example of the model constructed so far, and then apply it to the analysis of the effect of taxation, and in particular the comparison of joint with independent taxation, on the distribution of welfare within the household.

\footnotetext{
${ }^{6}$ This household welfare function is a generalisation of a proposal for modelling household choices made in Samuelson (1956). It contains as special cases both the Nash bargaining maximand and the weighted utilitarian formulation of Browning and Chiappori (1998). See Apps and Rees (2009b) for further discussion.
} 


\section{An Example}

We assume that the utility functions take the quasilinear form

$$
u_{i}=x_{i}+\varphi_{i}\left(y_{i}, z_{i}\right)
$$

where $\varphi_{i}($.$) is strictly concave and increasing. The implication of transferable$ utility gives a particularly simple form for the upper boundary of the household's utility possibility set, which we derive by solving the problem

$$
\begin{gathered}
\max _{x_{i} y_{i} z_{i}} u_{1}=x_{1}+\varphi_{1}\left(y_{1}, z_{1}\right) \\
\text { s.t. } x_{2}+\varphi_{2}\left(y_{2}, z_{2}\right) \geq u_{2}^{0} \\
\sum_{i=1}^{2}\left(x_{i}+p y_{i}+w_{i} z_{i}\right) \leq \sum_{i=1}^{2} w_{i}
\end{gathered}
$$

Then it is straightforward to show that the utility possibility set is given simply by

$$
\Omega=\left\{\left(u_{1}, u_{2}\right) ; \sum_{i} u_{i} \leq \sum_{i} w_{i}, u_{i} \geq 0\right\}
$$

To solve the household's allocation problem we take the HWF

$$
H=\left(\alpha\left(w_{1}, w_{2}\right) u_{1}^{1-\rho}+\left[1-\alpha\left(w_{1}, w_{2}\right)\right] u_{2}^{1-\rho}\right)^{\frac{1}{1-\rho}} \rho \in[0,1) \cup(1, \infty)
$$

with $\alpha(.) \in(0,1)$. We assume that $\alpha_{1}>0>\alpha_{2}$. The parameter $\rho$ is a measure of inequality aversion. It is then easy to show that maximising this HWF over the utility possibility set, and assuming that the self enforcement constraints defined by (16) are satisfied as inequalities by this solution, yields the household optimum

$$
\begin{aligned}
& u_{1}^{*}=\gamma \sum_{i} w_{i} \\
& u_{2}^{*}=(1-\gamma) \sum_{i} w_{i}
\end{aligned}
$$

where

$$
\gamma \equiv \frac{\left(\frac{\alpha}{1-\alpha}\right)^{\frac{1}{\rho}}}{1+\left(\frac{\alpha}{1-\alpha}\right)^{\frac{1}{\rho}}}
$$

Moreover, given the assumption on the derivatives of $\alpha($.$) , we have that \partial \gamma / \partial w_{1}>$ $0>\partial \gamma / \partial w_{2}$, implying, as we would expect, that an increase in $i$ 's wage rate improves her relative share in household consumption. We can regard (27) and (28) as defining the household sharing rule in utility terms.

The results above are useful for the subsequent discussion of taxation. First however we analyse further the nature of the HRC in this simple model. First note that, given that the form of the household's optimisation problem is the 
same in every period, it suffices to talk in terms of a stationary contract $a^{*}$ with associated values of labour supplies $l_{i}^{*}, h_{2}^{*}$, which yield $u_{i}^{*}$ as defined above, and are repeated in every period. We then have

Proposition 1: The stationary HRC yielding $\left(u_{1}^{*}, u_{2}^{*}\right)$ in each period is self enforcing if and only if it is supported by a value $b^{*}$ satisfying

$$
p y_{1}^{*}-\delta\left(u_{2}^{*}-u_{2}^{0}\right) /(1-\delta) \leq b^{*} \leq \delta\left(u_{1}^{*}-u_{1}^{0}\right) /(1-\delta)
$$

Proof: The IC constraints under a stationary HRC become

$$
u_{i}^{*} \geq(1-\delta) \hat{u}_{i}+\delta u_{i}^{0} \quad i=1,2
$$

We can show that

$$
\begin{gathered}
\hat{u}_{1}-u_{1}^{*}=b \\
\hat{u}_{2}-u_{2}^{*}=p y_{1}^{*}-b
\end{gathered}
$$

Substituting into the IC constraints and rearranging then gives the result. These simple results follow from the quasilinearity of the utility functions, since the optimal values of the $y_{i}$ and $z_{i}$ are fixed by the wage rates, and so reneging essentially changes only consumption, and therefore utility by the same amount. Reneging by 1 allows him to increase his consumption by $b$, reneging by 2 allows her to increase her consumption bythe value of what she supplies to 1 minus $b$. If therefore $p y_{1}^{*} \leq b$ she has no incentive to renege.

Corollary: The stationary HRC yielding $\left(u_{1}^{*}, u_{2}^{*}\right)$ in each period is self enforcing if and only if the total relationship surplus $S^{*} \geq(1-\delta) p y_{1}^{*} / \delta$.

Proof: Note that $S^{*} \equiv \sum_{i}\left(u_{i}^{*}-\hat{u}_{i}\right)$. Then if the inequality is not satisfied there cannot exist a $b^{*}$ satisfying the condition in Proposition 1.

\section{Taxation and the Household Income Distrib- ution}

In a recent paper ${ }^{7}$, Robert Pollak discusses the issue of joint vs individual income taxation and its effects on the distribution of income within the household, using as his theoretical framework models of one-shot Nash bargaining games. He comes to the conclusion that

In the absence of human capital effects, joint taxation does not appear to disadvantage women in either divorce threat or separate spheres bargaining. Hence, [the] claim that joint taxation disadvantages women, if it is correct, depends on effects that operate through the incentives to accumulate human capital.

\footnotetext{
${ }^{7}$ Pollak (2005). Gugl (2004) also discusses taxation in the context of a Nash bargaining model.
} 
A key assumption underlying these models is that binding agreements that support Pareto efficient outcomes are possible but, as discussed in the Introduction, this does not seem to be a reasonable assumption for the household. Thus we have proposed relational contracts as the appropriate theoretical framework. An important difference between the two sets of models is that in the Nash bargaining models, threat points fully determine the unique solution, whereas in relational contract models, they define the boundaries of the set of self enforceable contracts, but not the specific equilbrium choice within this set. ${ }^{8}$ Of course, if Nash bargaining were used to characterise the equilibrium relational contract then Pollak's conclusion would continue to apply. However, we have in this paper proposed a more general criterion for choice of the equilbrium contract, namely that the household seeks to maximise some form of household welfare function, which may give an interior solution that is not strictly determined by the threat points.

Using the model presented in the previous section, we now show that Pollak's conclusion does not hold in the type of model proposed here, given a reasonable interpretation of the stylised facts: in a progressive income tax system in which the marginal tax rate increases with income, individual taxation will give a higher utility level for the secondary worker than joint taxation. Since 70-80\% of secondary earners in households in North America and Europe are female, this essentially contradicts Pollak's conclusion. We now establish this formally.

Since we are interested only in the within-household and not the acrosshousehold welfare distribution, ${ }^{9}$ we can assume a "representative household" model. Let the $w_{i}$ now represent net of tax wages, given by

$$
w_{i}=\left(1-t_{i}\right) \hat{w}_{i} \quad i=1,2
$$

where $t_{i}$ is the marginal tax rate faced by $i$ and $\hat{w}_{i}$ is the gross wage. In a joint tax system the $t_{i}$ are of course equal, and so we can model a move to an individual tax system as being a differential tax reform with $d t_{1}>0>d t_{2}$. For example, this could come about from taxing primary and secondary earners' incomes separately but under the same piecewise linear system with increasing marginal tax rates across brackets,${ }^{10}$ or alternatively by moving to "genderbased taxation", as advocated by Alesina et al (2007).

It follows from revenue neutrality of the tax reform and the tax revenue constraint

$$
\sum_{i} t_{i} \hat{w}_{i} l_{i}=G
$$

where $G$ is a given constant, that

$$
d t_{1}=-\mu d t_{2}
$$

\footnotetext{
${ }^{8}$ Assuming of course that the maximum of the HWF does not occur at a boundary point. Consideration of this case would be interesting, but will be left for future work.

${ }^{9}$ This has been thoroughly analysed in Apps and Rees (1988), (1997), (1999) and (2007b).

${ }^{10}$ For a general analysis of these see Apps, Long and Rees (2009a).
} 
where $^{11}$

$$
\mu=\frac{\hat{w}_{2} l_{2}\left(1+\varepsilon_{2}\right)}{\hat{w}_{1} l_{1}\left(1+\varepsilon_{1}\right)}>0
$$

and

$$
\varepsilon_{i}=\frac{t_{i}}{l_{i}} \frac{\partial l_{i}}{\partial t_{i}}<0 \quad i=1,2
$$

We assume, as is empirically reasonable, that $\varepsilon_{i} \in(-1,0]$. Then the sign of $\mu$ simply reflects the condition that the tax rates are not on the wrong side of the Laffer curve. Moreover, as a stylised fact we have $\left|\varepsilon_{1}\right|<\left|\varepsilon_{2}\right|$, secondary earners have higher labour supply elasticities than primary earners. Thus it is reasonable to make the assumption $\mu<1$. Then we have

Proposition 2: On the given assumptions, a tax reform with $d t_{1}>0>d t_{2}$ certainly makes secondary earners better off, but may or may not make them better off relative to primary earners.

Proof: From the sharing rules in (27) and (28) we have

$$
\begin{gathered}
d u_{1}^{*}=\gamma \sum_{i} d w_{i}+\left[\frac{\partial \gamma}{\partial t_{1}} d t_{1}+\frac{\partial \gamma}{\partial t_{2}} d t_{2}\right] \sum_{i} w_{i} \\
d u_{2}^{*}=(1-\gamma) \sum_{i} d w_{i}-\left[\frac{\partial \gamma}{\partial t_{1}} d t_{1}+\frac{\partial \gamma}{\partial t_{2}} d t_{2}\right] \sum_{i} w_{i}
\end{gathered}
$$

We can show that

$$
\sum_{i} d w_{i}>0 \Leftrightarrow \hat{w}_{2}-\mu \hat{w}_{1}>0
$$

But this follows immediately from

$$
\frac{l_{1}}{l_{2}}>1>\frac{\left(1+\varepsilon_{2}\right)}{\left(1+\varepsilon_{1}\right)}
$$

Thus for both earners the first term is positive. From the earlier analysis we know that $\partial \gamma / \partial t_{1}<0<\partial \gamma / \partial t_{2}$. Thus the term in square brackets is strictly negative, implying that other things being equal the distribution of income within the household improves in favour of secondary earners. Thus secondary earners are certainly better off a as result of the change, but whether they gain more than primary earners depends on the value of $\gamma$. Thus we have

$$
d u_{2}^{*}-d u_{1}^{*}=(1-2 \gamma) \sum_{i} d w_{i}-\left[\frac{\partial \gamma}{\partial t_{1}} d t_{1}+\frac{\partial \gamma}{\partial t_{2}} d t_{2}\right] \sum_{i} w_{i}
$$

The second term is positive and the first is nonegative if $\gamma \leq 1 / 2$. Otherwise everything depends on relative magnitudes.

This proposition follows directly from the result that in the model an increase in $w_{2}$ and decrease in $w_{1}$ must increase 2 's share of income if we hold

\footnotetext{
${ }^{11}$ For simplicity, we assume $\partial l_{i} / \partial t_{j}=0, i \neq j$. This is close to reality since the evidence seems to show that $\partial l_{1} / \partial t_{2}=0$ while $\partial l_{2} / \partial t_{1}<0$ but is barely significant. Taking this latter into account would only strengthen the results given below.
} 
total household income constant. Under joint taxation, marginal tax rates of the two earners are equalised, whereas under progressive individual taxation, secondary earners will tend to have lower marginal rates than primary earners. Holding total household income constant therefore, moving from joint to individual taxation reduces the net of tax wage rates of primary earners and increases those of secondary earners. As long as it is the net of tax wage rates that determine the weights on individual utilities in the HWF, this must make secondary earners better off. The first terms in (39) and (40) could be thought of as a "Ramsey effect". Total household income net of tax increases because the tax rate is reduced on the earner with the higher labour supply elasiticity, so that this is purely an efficiency effect. The sizes of the relative gains from this effect depend on the initial distribution of power within the household. In any case, we see that in the type of model proposed in this paper, and in contrast to the results that Pollak shows emerge from nash bargaining models, joint taxation, under the given stylised facts, does disadvantage secondary earners, certainly absolutely and possibly relatively, and these are predominantly women.

\section{Conclusions}

The first contribution of this paper was to apply the theory of relational contracts to make precise the idea that because households are engaged in a repeated, if non-cooperative, game, we can rationalise Pareto efficient outcomes as being supported by self interest, given the specific pattern of specialisation and exchange which exists in the household. We characterise the household's choice of a particular solution from the resulting feasible set as being found from the maximisation of a household welfare function, which is a generalisation of a suggestion originally made by Samuelson. This nests as special cases the objective functions used in currently popular models of households engaged in one-shot cooperative games. We take a specific example of such a household welfare function, characterise the determinants of the household utility distribution, and then apply the model to examine the effects of a move from joint to individual taxation on this distribution. We show that given the standard stylised facts, secondary earners are always better off absolutely, and define the conditions under which they will also be so relatively. This confirms the con-

clusions from models which concern themselves only with the across-household welfare distribution.

\section{References}

[1] Abreu, D. (1986). "Extremal equilibria of oligopolistic supergames". Journal of Economic Theory, 39, 191-235. 
[2] Alesina, A., A. Ichino and L.Karabarbounis, (2007), "Gender based taxation and the division of family chores", Harvard University Discussion Paper.

[3] Apps, P. F. (1981), A Theory of Inequality and Taxation. Cambridge: Cambridge University Press.

[4] Apps, P.F., N. V. Long and R. Rees, (2009a). "Optimal piecewise linear taxation". Mimeo.

[5] Apps, P.F., and R. Rees, (1988), "Taxation and the household", Journal of Public Economics, 35, 355-369.

[6] Apps, P. F. and Rees, R. (1997), "On the taxation of trade within and between households", Journal of Public Economics,

[7] Apps, P. F. and Rees, R. (1999), "Joint vs individual taxation in models of household production", Journal of Political Economy, 107, 178-190.

[8] Apps, P.F., and R. Rees, (2007). "The taxation of couples". IZA Discussion Paper 2910.

[9] Apps, P.F., and R. Rees, (2009b). Public Economics and the Household. Cambridge: Cambridge University Press.

[10] Apps, P F, N. V. Long and R. Rees, (2009a) "Optimal piecewise linear income taxation", CESifo D P.

[11] Browning, M., and Chiappori, P.-A. (1998). "Efficient intra-household allocation: a characterisation and tests". Econometrica, 66 (6), 1241-1278.

[12] Chen, Z., and F. Woolley, (2001). "A Cournot-Nash model of family decision making". Economic Journal, 111(474), 722-748.

[13] Gugl, E, (2004), "Intrafamily distribution and taxation", National Tax Journal Papers and Proceedings.

[14] Levin, J., (2003) "Relational incentive contracts", American Economic Review, $93,3,835-856$.

[15] Lundberg, S. and R. A. Pollak, (1993). "Separate spheres bargaining and the marriage market". Journal of Political Economy, 101, 988-1010.

[16] Lundberg, S. and R. A. Pollak, (2003), "Efficiency in marriage", Review of Economics of the Household, 1, 3, 153-168.

[17] MacLeod, B W and J M Malcomson, (1989), "Implicit contracts, incentive compatibility and involuntary unemployment", Econometrica, 57, 2, 44780 .

[18] MacLeod, B W and J M Malcomson, (1998), "Motivation and markets", American Economic Review, 88, 3, 388-411. 
[19] Manser, M., and M. Brown,. (1980). "Marriage and household decision making: A bargaining analysis". International Economic Review, 21(1), 31-34.

[20] McElroy, M. B. and M. Horney,. (1981). "Nash-bargained decisions: Towards a generalization of the theory of demand". International Economic Review, 22, 333-349.

[21] McElroy, M. B. (1990). "The empirical content of Nash bargained household behaviour". Journal of Human Resources, (25)4, 559-583.

[22] Ott, N., (1992). Intrafamily Bargaining and Household Decisions. Berlin: Springer-Verlag.

[23] Pollak, R. A. (1985). "A transaction cost approach to families and households". Journal of Economic Literature, 23(2), 581-608.

[24] Pollak, R. A. (2005). "Family bargaining and taxes: A prolegomenon to the analysis of joint taxation" Washington University Discussion Paper

[25] Samuelson, P. A. (1956). "Social indifference curves". Quarterly Journal of Economics, 70, 1-22. 